THE INDUSTRIAL INSTITUTE FOR ECONOMIC AND SOCIAL RESEARCH

WORKING PAPER No. 464, 1996

MULTINATIONALS WITHOUT ADVANTAGES

BY MASSIMO MOTTA 


\title{
Multinationals without advantages *
}

\author{
Massimo Motta ${ }^{\dagger}$ \\ Universitat Pompeu Fabra \\ VERY PRELIMINARY
}

10 May 1996

\begin{abstract}
We propose a simple model to analyze the widespread idea that a necessary condition for firms to make foreign direct investments is that they have firm-specific advantages with respect to host country firms. We show that no such advantages are necessary to become multinationals. Further, firms might be induced to invest abroad to acquire new advantages, rather than exploiting existing ones. For this reason, foreign direct investment might occur even in the absence of exporting costs and lower production costs in the host country. Firms endowed with lower quality might make direct investments to benefit from technological spillovers which arise when manufacturing subsidiaries are close, whereas high quality firms might prefer not to invest abroad to avoid dissipation of their advantages.
\end{abstract}

"This paper has been written for the Workshop on "Multinationals, Trade and Economic Geography", held at IUI, Stockholm, 23-24 May 1996. I would like to thank Georges Siotis, with whom I am working on a related project, for the many discussions on the topic. I am also extremely grateful to Antonio Ciccone, living proof that externalities do exist, for his insightful comments and the many stimulating discussions. Obviously, I am solely responsible for all the errors and omissions.

${ }^{\dagger}$ Correspondence to Massimo Motta, Department of Economics, Balmes 132, E-08008 Barcelona (Spain); e-mail: motta@upf.es 


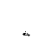




\section{Introduction}

The dominant literature on foreign direct investments is based on an idea first developed by Hymer in 1960 (see Hymer (1976)). According to Hymer, a firm which decides to establish a subsidiary abroad suffer many disadvantages and difficulties with respect to local firms. Possible examples of such difficulties are a scarce knowledge of the host market demand; of the host country's laws and regulations; a scarce familiarity with different cultural, social and business environments; language difficulties; possible discrimination from consumers having preferences for domestic goods and governments which assign public procurement to favour local firms. One should then explain why a firm would like to invest abroad despite such "barriers to entry". Hymer identified three reasons for it. They roughly correspond to three different types of foreign direct investment (fdi).

- Foreign investments to remove "oligopolistic conflicts". In sectors which are concentrated internationally, a fdi might represent a way to increase market power by reducing competition. This holds good both for horizontal fdi (taking over a rival which threatens market shares or price wars) and for vertical fdi (controlling a supplier of intermediate inputs or raw materials).

- Foreign investments to exploit firm specific advantages, namely advantages in terms of more skilled management, of production (technological knowledge and know-how), of commercialization (abilities in distribution and marketing), and related to the quality of the product (brand name, reputation for quality and reliability). Such advantages enable the firm to overcome the barriers to entry, by making foreign investment feasible (and more profitable than exports, in the presence of barriers to trade).

- Foreign investment of diversification. To diversify risk, a firm might decide to invest in a sector whose expected profits are not positively correlated to the main sector of activity. Risk spreading is even higher when investing in another country, where exogenous shocks are likely to be non-correlated with home country shocks.

The first type of fdi clearly deals with strategic interactions, and has become the object of study only recently, owing to the developments in oligopoly models which apply game theory concepts. In this vein, see Smith 
(1987), Horstmann and Markusen (1992), Motta (1992, 1994) among the others. The third type of fdi did not receive much attention either, and the same Hymer indicates that for the purpose of diversifying risk, control is not necessary, and it would be more efficient to diversify risk through portfolio investment rather than direct investment. Following work on fdi and multinational firms developed instead the second motive for fdi, and the dominant literature on fdi and multinationals is probably best expressed by the "eclectic paradigm" of Dunning which states that there exist three conditions which must all be satisfied for a firm to make fdi. The first is that there must be a firm specific (or "ownership") advantage. The second that there must be a location advantage (that is, the firm must prefer investment to exports). The third, that it must prefer exploiting its assets "internally" rather than licensing them to outside firms located in the host country.

This paradigm is still the point of reference for many scholars of fdi. In particular, the view that firm specific advantages are a necessary condition for fdi has rarely been challenged ${ }^{1}$. Yet, it is not clear what exactly a firm specific advantage means in this literature. Indeed, its contributions are not set in the context of formal models and the lack of a rigorous framework creates some ambiguity.

The purpose of this paper is to try to analyze in a formal framework the argument that a firm might make foreign direct investments only if it possesses some "advantages". We show that this is not necessarily the case, for at least two reaons. The first is that a firm might invest abroad even if it provides a good whose quality is inferior, as long as there exists some demand for it. The second, and probably more compelling, is that a firm might decide to go abroad not so much to exploit some advantages which it already possesses but rather to acquire new ones. To this purpose, we show that a firm might be attracted abroad by the existence of firms which have superior quality or technology. This occurs when, by establishing production where the high quality firms are located, the investing firm benefits from spillovers. As a corollary of this result, the establishement of a subsidiary abroad might even be per se unprofitable. However, the benefit from local externalities might improve the technology and the product of the investing firm which can then incorporate the improvement obtained in all the markets

\footnotetext{
${ }^{1}$ Markusen (1995), in an authoritative survey of the recent literature on multinational firms, says that "(..) The multinational firm must, therefore, arise due to the fact that it possesses some special advantage such as superior technology or lower costs due to scale economies. This point is found in Hymer's 1960 dissertation, and the logic of the argument remains persuasive (page 173)."
} 
where it sells, earning profits which outweigh the possible losses from running the foreign venture.

Although it has not attracted the attention of many scholars, the argument that firms make fdi to benefit from advanced business or technological environments is not new, and it has received some support from both anecdotal and even empirical evidence (see Neven and Siotis (1995)). The idea that technological spillovers should be a relevant element in the study of multinational firms, and in particular of its effects, is a well documented one (see Blomström and Kokko (1996)). Finally, recent work on the "new economic geography" has emphasised the idea that externalities play an important role in determining the location choice of the firms. Although from a different perspective, the present paper is related to this strand of the literature as well.

The paper is organized in the following way. The next section 2 introduces a very simple model. Section 3 shows that firm-specific advantages are not necessary conditions for fdi, and that a firm might invest abroad to benefit from technological spillovers. Section 4 extends the model to analyze a game where not only a low quality firm but also a high quality firm has to take decisions about whether to export or invest abroad. It is found that the latter might find it profitable not to make a fdi to avoid dissipation of its advantages in favour of host country firms. Section 5 concludes the paper.

\section{The model}

Let us consider two countries $A$ and $B$. In each of these two countries there exists a local firm: firm 1 is established in country $A$, and firm 2 in country $B$. The firms are incumbent in their domestic market and have already sunk the fixed costs necessary for the development of the product and for local supply when the game starts. These firms do not necessarily have the same quality or technological level, as we specify below. The two countries are different in their population (or market) sizes, but are identical in all other respects. Variable costs of production are the same independently of the country where production is located and we also assume that they are constant and identical for the two firms. For simplicity, and without loss of generality, we assume that they are equal to zero.

The two countries' citizens have the same preferences, described by the 
following utility function of the representative consumer:

$$
V\left(q_{i}, q_{j}\right)=a_{i} q_{i}+a_{j} q_{j}-\frac{q_{i}^{2}}{2}-\frac{q_{j}^{2}}{2}-g q_{i} q_{j}
$$

where $q_{i}, q_{j}$ are the quantities of the differentiated good produced by firm $i$ and firm $j$ respectively $(i, j=1,2, i \neq j)$. The parameters $a_{i}$, and $a_{j}$ are positive and might be interpreted as the willingness to pay for the good. We shall assume that $a_{1} \geq a_{2}$, thus implying that good 1 is regarded by all consumers as being of higher quality than the good produced by firm 2 . Although consumers unanimously rank the quality of the goods, this is not a pure vertical differentiation model, since when prices are equal the demand for the low quality good is not necessarily zero. This is therefore a model where elements of horizontal and vertical product differentiation coexist.

We focus on the case where goods are demand substitutes, and therefore assume that $0 \leq g \leq 1$. The parameter $g$ represents the degree of substitutability between goods: As $g$ tends to zero, the two goods are seen as less substitutes by consumers; as $g$ tends to one, the goods become very close substitutes. This parameter can also be interpreted as an inverse measure of product differentiation (see for instance Singh and Vives (1984)). However, when interpreting comparative static exercises which involve such a parameter, one should take into account that a reduction in $g$ increases the global expenditure of the consumers. In other words, an increase in product differentiation also expands the market demand for the good, a result obtained in many models of product differentiation. ${ }^{2}$ It is possible to rewrite the demand functions to make sure that the parameter $g$ does not affect aggregate demand, but this would make calculations more complex without adding much to the analysis.

From the problem of maximization of the utility of the consumers, we obtain the following demand functions:

$$
p_{i}=a_{i}-\frac{q_{i}}{S_{k}}-g \frac{q_{j}}{S_{k}}
$$

where $S_{k}$ is the size of the market of country $k=A, B$.

\footnotetext{
${ }^{2}$ Think for instance of a Hotelling-type model where consumers have finite reservation prices. Technically, this amounts to assuming that the market is not necessarily covered. In such a situation when firms choose to locate more apart from each other some consumers who were not previously buying the good will now find a product closer to their location and start to buy. Market demand therefore increases as a result of the decision of the firms to differentiate from each other.
} 
Proof.

Consider the problem of maximization of the utility of a single consumer. The individual demand of a consumer $k$ for good $i$ is given by:

$$
p_{i}=a_{i}-q_{i k}-g q_{j k}, \quad(i, j=1,2, i \neq j) .
$$

By inverting this system, one obtains the quantity demanded by an individual consumer $k$ to firm $i$ as:

$$
d_{i k}=\frac{a_{i}-g a_{j}-p_{i}+g p_{j}}{1-g^{2}} .
$$

Therefore, the demand faced by firm $i$ in a market where there exists a number $S_{k}$ of identical consumers is given by $q_{i}=S_{k} d_{i k}$. By inverting again the system of direct demand functions, one obtains the (inverse) demand functions given above.

Endowed with such demand functions, we now proceed to analyze some games where firms decide on whether to export or invest abroad.

\section{Are firm-specific advantages necessary to in- vest abroad?}

As we have discussed in the introduction, it is usually claimed that in order for a firm to invest abroad, it must possess some firm-specific assets which give it an advantage with respect to the firm(s) located in the foreign market. In our model, the existence of an advantage might take two forms. The first is when a firm $i$ has a higher value of $a_{i}$, that is a superior quality for which consumers are willing to pay more. The second - less straightforward - is when a firm has some kind of captive market whenever products are differentiated $(g<1)$. In this case, the advantage would consist of producing a variety which is perceived by consumers as being less of a perfect substitute with respect to the other product.

In this section, we want to show that:

- Foreign direct investments (fdi) are made even when neither of the two conditions above are fulfilled, that is when no firm-specific advantages in the sense just described exist.

- Foreign direct investments might allow a firm to acquire new advantages which it would not be able to get by exporting. As a corollary, we 
also show that a firm might decide to invest abroad even when none of the traditional reasons for making fdi exists. In particular, when production costs are identical and there are no additional transportation costs which should be paid by exporting.

To illustrate such results, we want to rely on the simplest possible model. We assume that the quality levels of the firms are exogenously given, in the sense that firms do not have to choose the R\&D levels which determine qualities. Such qualities are determined by historical reasons, or past decisions by the firms which for the moment we do not consider. Qualities are a public good within a firm, in the sense that a new subsidiary would be able to produce exactly the same quality level as all the other existing subsidiaries of the same firm. We also assume that the "high quality" firm 1 is located in country $A$ and it exports to market $B$. In other words, we do not consider the possibility that the high quality firm makes a fdi in the other market (we relax this assumption in the next section). We focus therefore on the internationalization decisions of the "low quality" firm 2 whose quality $\overline{a_{2}} \leq \overline{a_{1}}$. The game is as follows.

In the first stage, firm 2 decides whether it wants to export or invest in market $A .{ }^{3}$ If it exports, it incurs a transportation cost which we model as an iceberg cost $t \geq 1$. Note that in our formulation, this amounts to sxying that for each given price $p_{i}$, a foreign consumer will not receive $d_{i}$ units of good $i$, but only $\frac{d_{i}}{t}$ units of it. Hence, the presence of transportation costs works as a reduction of the effective market size $\frac{S_{k}}{t}$ for the firm. For instance, when firm 2 exports to market $A$, the demand functions for the two firms in this market are given by:

$$
p_{1}=\overline{a_{1}}-\frac{q_{1}}{S_{A}}-g \frac{q_{2}}{S_{A} / t} ; \quad p_{2}=\overline{a_{2}}-\frac{q_{2}}{S_{A} / t}-g \frac{q_{1}}{S_{A}} .
$$

If firm 2 decides to invest in market 1 , it will not incur any transportation cost, since it will be as "local" as the domestic firm. However, it will have to incur some fixed costs $F$ which might include all set-up costs (creating a plant, buying equipment and machines and so on) as well as all the "information" costs which are involved in the decision of starting operating in a country whose business environment, law and markets are less well known.

To incorporate the idea that the firm might benefit from some externalities when producing in the same location as the other firm, or that there

\footnotetext{
${ }^{3}$ For simplicity, we assume parameter values such that the low quality firm always serves both the domestic and the foreign market. Such assumption will be removed in the next section.
} 
exists some spillover which can be appropriated only when production facilities are located next to each other, we assume that when firm 2 invests in market $A$, its quality level goes to $a_{2}=\overline{a_{2}}+\lambda\left(\overline{a_{1}}-\overline{a_{2}}\right)$. Therefore, the parameter $\lambda \in[0,1]$ is a measure of the degree of spillovers in the industry. The demand functions faced by the two firms when firm 2 invests in market $A$ are therefore given by:

$$
p_{1}=\overline{a_{1}}-\frac{q_{1}}{S_{A}}-g \frac{q_{2}}{S_{A}} ; \quad p_{2}=a_{2}-\frac{q_{2}}{S_{A}}-g \frac{q_{1}}{S_{A}} .
$$

In the second stage of the game, firms compete in quantities for any given supply configuration chosen at the first stage of the game.

Since we are interested in the subgame perfect equilibrium of the game, we work backwards and look first for the solution of the product market subgame. We assume that $\overline{a_{2}} \geq \frac{g \overline{a_{1}}}{2}$, to guarantee that firm 2 is at least able to serve the foreign market through exports. There exist therefore only two different supply configurations.

- Firm 2 invests in market $A$. In such a case, firms 1 and 2 earn respectively:

$$
\Pi_{1}^{e f}=\frac{\left(2 \overline{a_{1}}-g a_{2}\right)^{2}\left(S_{A}+S_{B} / t\right)}{\left(4-g^{2}\right)^{2}} ; \quad \Pi_{2}^{e f}=\frac{\left(2 a_{2}-g \overline{a_{1}}\right)^{2}\left(S_{A}+S_{B}\right)}{\left(4-g^{2}\right)^{2}}-F,
$$

where the index ef refers to the fact that firm 1 is exporting (e) and firm 2 is making a fdi $(f)$.

- Firm 2 exports to market $A$. In such a case, firms 1 and 2 earn respectively:

$$
\Pi_{1}^{e e}=\frac{\left(2 \overline{a_{1}}-g \overline{a_{2}}\right)^{2}\left(S_{A}+S_{B} / t\right)}{\left(4-g^{2}\right)^{2}} ; \quad \Pi_{2}^{e e}=\frac{\left(2 \overline{a_{2}}-g \overline{a_{1}}\right)^{2}\left(S_{A} / t+S_{B}\right)}{\left(4-g^{2}\right)^{2}},
$$

where the index ee refers to the fact that both firms are exporting (e).

Since the decision by firm 1 is not an issue in this section, the equilibrium with firm 2 investing rather than exporting prevails according as whether $\Pi_{2}^{e f}>\Pi_{2}^{e e}$. To simplify the expressions, we denote from now on $\overline{a_{1}}=k \overline{a_{2}}$, $S_{A}=\mu S$, and $S_{B}=(1-\mu) S$. Therefore, $k \geq 1$ indicates the ratio between the high and the low quality, being the gap between the two firms larger as this parameter increases; $S$ is the aggregate market size of the two economies; $\mu$ is the share of the aggregate population which is resident in country $A$. 
To simplify things, we assume that country $A$ is larger, that is $\mu \geq 1 / 2$. The assumption that firm 2 always finds it profitable to export can be rewritten as $k<2 / g$.

We can then say that the fdi strategy is preferred to exports when:

$$
(2+2 \lambda(k-1)-g k)^{2}-(2-g k)^{2}(1-\mu+\mu / t)>F \frac{\left(4-g^{2}\right)^{2}}{{\overline{a_{2}}}^{2} S} .
$$

We now turn to the analysis of this condition.

\subsection{On firm specific advantages and foreign direct invest- ments}

It is obvious that there exist parameter values for which the condition above holds, and for which foreign investment would be the equilibrium strategy. Before examining in details how the different parameters affect the decision between fdi and exports, let us first of all show that firm-specific advantages by firm 2 are by no means a necessary condition for the feasibility of the fdi strategy. To do so, consider the case where $k$ is strictly lower than one, $g=1$, and $\lambda=0$. In such circumstances, firm 2 has a disadvantage with respect to firm 1 , the goods are perfectly substitutable and there is no externality which might push the firm toward investing abroad ${ }^{4}$.

The above condition becomes:

$$
(2-k)^{2} \mu(1-1 / t)>\frac{9 F}{\overline{a_{2}^{2}} S} .
$$

It is clear that there exist combinations of parameter values for which the condition is satisfied. This shows that firm specific advantages are not a necessary condition for investing abroad ${ }^{5}$.

\footnotetext{
${ }^{4}$ Note that despite the fact that the goods are perfectly substitutable and firm 2 has a disadvantage, the firm still manages to sell. This is because competition is in quantities. This case is very similar to the case where two firms are selling a homogeneous good and have different production costs. As long as the difference in costs is not "too" large, the less efficient firm has a positive share of the market, even though this is smaller than the rival's. Indeed, we could restate our model in terms of advantages related to process instead of product technology.

${ }^{5}$ One might wonder why a domestic firm does not enter market $A$ instead of the foreign firm from country $B$. A partial explanation could be given by the fact that the foreign firm has already incurred some fixed sunk costs which are necessary to exist as a firm or to create the minimum level of quality indispensable to sell in the industry. But this would imply giving an implicit "advantage" to the foreign firm over the domestic potential
} 


\subsection{Foreign direct investments to acquire advantages}

We now turn to our second claim, namely that foreign direct investments can be seen as an instrument which allows a firm to acquire new advantages. This result is somehow built-in in our model, since we assume that by making a fdi the firm can benefit from spillovers whereas by exporting it cannot benefit from such an externality. Indeed, by looking at the condition for fdi above, it appears that in the presence of possible externalities, choosing to locate in the market where the high quality firm produces would increase the profit of the low quality firm. However, it is probably more interesting to note that the existence of spillovers might represent a good reason for a firm to invest abroad even in the absence of any traditional motive for fdi.

Consider the case where $t=1$. This amounts to saying that there exist no transportation costs. Since we have assumed that production costs are identical in both countries, this means that foreign direct investments cannot be due to either production or transportation cost savings (since transportation costs and tariffs or other protectionist measures would be modeled in the same way, this means that tariff-jumping fdi cannot occur here either).

The above condition for having fdi can then be written as:

$$
(2-g k+2 \lambda(k-1))^{2}-(2-g k)^{2}>F \frac{\left(4-g^{2}\right)^{2}}{{\overline{a_{2}}}^{2} S} .
$$

When spillovers are nihil $(\lambda=0)$ and/or when there is nothing to be learned from the other firm $(k=1)$, this condition is never satisfied. When instead spillovers are positive and there exists a tecnological difference between the local high quality and country $B$ low quality firm, then fdi might be the equilibrium choice of the latter (the LHS of the inequality becomes positive and can be higher than the RHS). What happens here is that by making the foreign investment, the firm benefits from a spillover which increases its own level of quality. In turn, since quality is a public good within

entrants. The best way to deal with this problem is then to consider a homogeneous good market where both a domestic potential entrant and the foreign firm could enter, by paying some fixed costs which might be larger for the latter than for the former. This setting has been studied by Motta (1992). For intermediate values of market size, it is shown there that only one firm might profitably enter the market, that is, there exist multiple equilibria where either the domestic or the foreign firm enters and the other stays out, credibly deterred by the entry of the rival. This shows that fdi might occur as an equilibrium strategy even when there exist other domestic firms which can enter the industry and over which the foreign firm does not have any superiority. The same result could be replicated in the setting of the present paper. 
the different subsidiaries of the firm, not only the production in the foreign country $A$, but also that in the home country $B$ will incorporate the higher quality. This also means that the decision of making a fdi in country $A$ might be unprofitable per se but perfectly profitable on the whole. In other words, a foreign venture might be established even if the costs are higher than the benefits it yields, provided it grants the firm an asset which can be used in other markets. We have then showed that a firm can invest abroad to acquire new advantages, which can then be exploited in all the markets in which the firm sells.

\subsection{Variables affecting the decision of internationalization}

Let us now look back at the general condition which determines the choice of the firm between fdi and exports and study the variables which might affect such a decision. They are the following.

- The absolute size of the market, $S$, is a first variable which is important in determining the choice of the firm. The higher $S$, other things being equal, and the more likely that the firm will make a fdi. A bigger market implies that the firm can better recover the fixed sunk costs $F$ of the investment. The same is true for the variable which determines the share of the world population $\mu$ which is located in market $A$. This also increases the host market size. The impact of both variables $\mu$ and $S$ is extremely straightforward and intuitive, and has already been underlined in past contributions (see for instance Motta(1992)). There is little doubt that actual decisions by firms as to invest abroad take into account both the current and the expected size of the host markets. At an extremely aggregate level, this can also be seen through the fact that the vast majority of foreign direct investments are directed towards the most developed countries. According to Hummels and Stern (1994), $75 \%$ of the stocks of world fdi in 1985 are concentrated in the most developed economies (whose market size is larger, because of the higher spending power of their residents). From the empirical point of view, one should observe a positive correlation between GDP and inward fdi flows.

- The more important the fixed cost of setting up a plant abroad $F$ and the more costly to supply the local market through fdi. This can be seen as a measure of the importance of plant-level scale economies, and there exists some evidence that such economies tend to be negatively 
correlated to fdi. However, the variable $F$ include not only set-up costs associated to the establishment of physical production but also costs which are possibly associated to starting business in an environment which is less known than the domestic one. It is likely that such costs (although not necessarily paid once and for all) are independent of the volume of production and therefore might be considered as fixed costs of establishing a plant abroad. If this interpretation is accepted, one should expect to find that elements such as common language, similar culture and social habits, past business relationships and so on should decrease the value of $F$, other things being equal. Obviously, such variables are not easy to capture from a quantitative point of view. If anything, geographical distance might be a possible proxy for them and one could expect that the closer two countries, the lower the costs of establishing a subsidiary there. One might also expect that such fixed costs of establishing a subsidiary abroad also depend on firmspecific elements, such as skills of the managers, their experience and so on. From this point of yiew, the finding that there exists a minimum threshold size for going multinationals and that corporate age also matters (Markusen (1995)) is not entirely surprising. A country like Italy accounts for very little of the stock of world fdi $(1.7 \%$ in 1985 , according to Hummels and Stern (1994)) and this has probably to do with the fact that Italian industries are characterised by the importance of small and medium sized enterprises which are usually family businesses. For these firms is comparatively more difficult to have the necessary skills and pieces of information necessary to establish ventures abroad.

- Higher transportation costs and other barriers to trade $t$ make exports more expensive and therefore increase the likelihood that the foreign market is served via fdi. Again, from the theoretical point of view the impact that this variable plays on fdi is straightforward. Yet, there exists mixed evidence that the level of trade barriers is positively correlated with trade. It seems that when $t$ rises, both exports and fdi decrease. This ambiguous result might not be entirely surprising if the proxies for trade barriers are positively correlated to the factors that increase the costs of making fdi, as described above. For instance, many studies have proxied freight factors by using physical distances between countries (reported in Brainard (1993,p.19)). By doing so, one is overlooking that the cost $F$ of establishing a business in a far away 
country is likely to be higher than that of establishing it in a country which is closer. Geographical proximity does increase knowledge of the business environment of foreign countries. More generally, though, it is likely that transportation costs might be correlated with the distance variable, and the same might be true for tariff and non-tariff barriers (which are of difficult quantification, though), since openness of a country might be related with the knowledge of its market and business environment. Brainard (1993) does not explicitly recognises the possibility that tariff barriers might be correlated with the variable $F$, but she uses freight data not proxied by a distance variable, tariff barrier measures from a GATT database and non-tariff barriers from a survey, and she finds results which tend to suggest that there exists a substitution effect from exports toward sales of foreign affiliates when trade barriers rise.

- In our simple model, a decrease of the parameter $g$ affects positively the decsion of fdi. This is because a lower value of $g$ increases product differentiation (as well as the aggregate demand for the good) and therefore raises the profit associated with both fdi and export strategies. However, the former increases more than the latter. Note that the same effect holds for the parameter $\overline{a_{2}}$. An increase in this parameter increases proportionally export profits and fdi gross profits. But for a given fixed cost $F$ of fdi, this implies that the fdi strategy becomes more appealing. In general, we should expect that factors that increase a firm's profitability would give it an incentive to switch to a fdi strategy, since they would allow the firm to pass the minimum threshold which is necessary to cover fixed costs. Empirically, it does turn out that fdi tends to be more important in industries characterized by the existence of a large degree of product differentiation and of high ratios advertising/sales and R\&D/sales, which would both increase the willingness to pay for the goods of consumers (Markusen (1995)).

- If one looks at the effect of the variable $k$, which summarizes the quality differences between the firms, on the fdi versus export decisions, no clear result emerges. The sign of the derivative of $\left(\Pi_{2}^{e f}-\Pi_{2}^{e e}\right)$ with respect to $k$ changes with the parameter values. This is because two effects play here in different directions. On the one hand, an increase in the quality gap between the firms reduces proportionally the profits 
of exporting and the gross profits of fdi, by making more difficult for the fdi strategy to cover fixed costs. On the other hand, if there are spillovers, an increase in the quality of firm 1's product other things being equal would increase the profitability of making an investment. Spillovers allow firm 2 to appropriate part of the quality of the rival and make fdi more attractive. Therefore, when spillover effects are absent $(\lambda=0)$ an increase in the technological gap $k$ would make fdi unambiguously less likely. But when spillovers are positive the "technological sourcing effect" comes into play and the sign of the derivative is not clear any longer. It is therefore not clear a priori whether we should expect variables such as ratios or differences in R\&D or advertising levels between home and foreign firms to be negatively or positively correlated with fdi.

\section{When both firms can invest abroad}

In the previous section, we have limited our attention to the case where only the low quality firm can choose between foreign direct investments and exports, whereas the high quality firm can only export to the other country. This has been done for simplicity, and to show how the different parameters affect the fdi v. export choice in an analytical way. It is now time to widen the strategy set of the players and to try and analyze a slightly more complex game.

We consider the following two-stage game. In the first stage of the game, the two firms simultaneously decide about their mode of internationalization. They have to decide whether to serve the foreign market by exports or by local production. In the case of the low quality firm, however, the strategy space must include also the possibility not to sell anything. This is because when the quality gap is too high, the exporting and fdi strategy might give rise to negative profits (both on the domestic and the foreign markets) so the firm might be better off not selling at all. In the case of the high quality firm, instead, exporting is always profitable (this is because of the way we model iceberg transportation costs) and therefore we do not have to consider the additional strategy where firm 1 does not sell abroad. Table 1 indicates the normal form of the first stage of the game.

In the second stage of the game the firms compete in the product markets by simultaneously choosing quantities, conditional on the supply configuration which arises from the first stage. As usual, we solve backwards to find 
Table 1: Payoff Matrix of the supply game

\begin{tabular}{c|c|c|c|} 
firm 1 / firm 2 & fdi & $\exp$ & $\Phi$ \\
\hline fdi & $\Pi_{1}^{f f}, \Pi_{2}^{f f}$ & $\Pi_{1}^{f e}, \Pi_{2}^{f e}$ & $\Pi_{1}^{f \phi}, 0$ \\
\hline $\exp$ & $\Pi_{1}^{e f}, \Pi_{2}^{e f}$ & $\Pi_{1}^{e e}, \Pi_{2}^{e e}$ & $\Pi_{1}^{e \phi}, 0$ \\
\hline
\end{tabular}

the equilibria of the game. There exist six possible configurations for which we have to compute the Cournot equilibria.

- Both firms make a fdi in the other country. In this case, profits for the two firms are given by:

$$
\Pi_{1}^{f f}=\frac{\left(2 \overline{a_{1}}-g a_{2}\right)^{2}\left(S_{A}+S_{B}\right)}{\left(4-g^{2}\right)^{2}}-F ; \quad \Pi_{2}^{f f}=\frac{\left(2 a_{2}-g \overline{a_{1}}\right)^{2}\left(S_{A}+S_{B}\right)}{\left(4-g^{2}\right)^{2}}-F .
$$

- Firm 1 invests abroad while firm 2 exports. This gives profits:

$$
\Pi_{1}^{f e}=\frac{\left(2 \overline{a_{1}}-g a_{2}\right)^{2}\left(S_{A}+S_{B}\right)}{\left(4-g^{2}\right)^{2}} ; \quad \Pi_{2}^{e f}=\frac{\left(2 a_{2}-g \overline{a_{1}}\right)^{2}\left(S_{A}+S_{B} / t\right)}{\left(4-g^{2}\right)^{2}} .
$$

- Firm 1 invests abroad while firm 2 does not sell in either market:

$$
\Pi_{1}^{f \phi}=\frac{\left(\overline{a_{1}}\right)^{2}\left(S_{A}+S_{B}\right)}{4}-F ; \quad \Pi_{2}^{f \phi}=0 .
$$

- Firm 1 exports and firm 2 invests abroad: payoffs have been already given above.

- Both firms export: payoffs have been already given above.

- Firm 1 exports and firm 2 does not sell in either market:

$$
\Pi_{1}^{e \phi}=\frac{\left(\overline{a_{1}}\right)^{2}\left(S_{A}+S_{B} / t\right)}{4} ; \quad \Pi_{2}^{e \phi}=0
$$

After having computed the equilibrium solutions of the quantity game, we should now compute the equilibrium of the supply mode sub-game. Obviously, the equilibrium configurations will be different according to the different values taken by the parameters. To simplify the presentation and to discuss how the different parameters affect the equilibrium solutions, we 
proceed in the following way. We fix the values of all but two parameters and analyze the solutions in the plan. One can then make comparative statics exercises by seeing how changes in the value of one of the previously fixed parameters are going to affect the solutions. This does not give a complete picture of all the possible equilibrium configurations which possibly arise, but allows us to gain insight about both the shape of the equilibria and the way they are affected by the different parameters.

Figure 1 indicates the equilibria of the game in a plan where the relative size of country $A(\mu)$ is on the X-axis, and relative quality of firm $1(k)$ is on the Y-axis. We have drawn the lines which determine the choice of the firms between the different modes for given values of the parameters. Note in particular that $\lambda=0$ in this figure, which means that there exist no spillovers. The results can be interpreted in the following way. Start first with the region where $k$ is close to 1 and $\mu$ is close to .5. For such values, the firms provide a very similar quality, and the countries are of similar market size, since both of them have roughly one half of the world market size. In this region, both firms find it profitable to establish a subsidiary abroad and the equilibrium configurations is given by $f f$.

Let us now keep unchanged the relative market size parameter $\mu$ and consider what happens when the quality gap between the two products ircreases. When $k$ rises, the low quality firm is becoming less competitive and earn lower profits. Eventually, this entails that the profits earned would not be enough to recover the fixed costs of the investment, and the equilibrium shifts from $f f$ to $f e$. A further rise in $k$ decreases still more the competitivity of firm 2 and the profit it can earn in both markets. When the quality gap becomes very large, firm 2 will not be able to convince any consumer to buy its good, and the only equilibrium we can get is $f \phi$, one in which the low quality firm prefers not to sell.

Let us now doing a similar experiment by keeping unchanged the value of $k$ and modifying the relative market size parameter. The effect of this is clear: a rise in $\mu$ means that the market size of country $A$ becomes larger and that of country $B$ smaller. Other things equal, this increases the attractiveness of an export strategy by firm 1 and of a fdi strategy by firm 2 . These effects can be observed by considering successive equilibrium configurations along a horizontal movement. For instance, for $k=1.5$, one observes first an equilibrium where firm 1 invests and firm 2 exports $(f e)$; then one where the latter shifts to fdi $(f f)$; and finally a region where the equilibrium is one where the high quality firm exports and the other invests $(e f)$. 
Now that we have built this benchmark case we can analyze how changes in the value of the parameters (one at time, for this comparative statics exercise to make sense) affect the equilibrium configurations of the game. We are especially interested in studying the effects of spillovers, which in the first figure we have assumed away. Figure 2 describes the equilibrium solutions of the game for $\lambda=.1$. Note in particular that the presence of spillovers introduces a link between the two markets which was absent in the case where $\lambda=0$. In the latter case, the foreign mode strategy that each firm chooses is completely independent of the strategy that the other firm chooses. If a firm finds it profitable to export when the other firm exports, it will also find it profitable to export if the other firm invests. This is because neither production costs not profits in one market are related to those in the other. On the contrary, when an externality arises, the two markets are interrelated. For instance, if firm 1 decides to invest in country $B$, this is going to increase the quality of the product of firm 2 in both markets, via the spillover. Hence, the decisions between exporting and fdi can now be different according to the strategy adopted by the rival. This implies that there are now two lines which describe the indifference between exports and fdi for each firm, where there is only one line when $\lambda=0$.

There exist two areas in the plan where there are no equilibria in pure strategies. In such areas, firm 1 would like to invest only if the other firm invests. Indeed, when firm 2 exports, the investment by firm 1 would make firm 2 appropriate some of its superior quality and would therefore reduce firm 1's profit. On the contrary, firm 2 prefers to export only if firm 1 invests: if the latter invests, then there is no need for firm 2 to pay the fixed cost of the fdi, since it benefits already from the technological spillover. However, if firm 1 exported, then firm 2 would be better off by making a fdi which would allow it to increase the quality of its product. As a result of these preferences, only an equilibrium in mixed strategies (which we do not analyze) would arise here.

To see what are the effects of this change in the spillover parameter, look at Figure 3, where we have emphasized the changes in equilibrium configurations which occur in the various regions (in other regions no change occurs). There are three different types of modifications in supply configurations which can occur (we do not consider the areas where no pure strategy equilibrium exists under positive spillovers).

- Because of the spillovers which would increase the quality of the rival, and thus decrease its own profit, firm 1 does not invest abroad in 
regions where it would have made a fdi had $\lambda$ been equal to zero. These happens in the following cases:

- From $f \phi$ to $e \phi$

- From fe to ee;

- From fe to ef;

- From $f f$ to $e f$.

- Knowing that by investing abroad it would be able to increase its quality, firm 2 makes what we could call a technology sourcing fdi. It invests abroad for values of the parameters for which it would not have invested in the absence of spillovers. This effect occurs in the following regions:

- From ee to ef;

- From fe to $f f$;

- From fe to $e f$.

- Finally, there exists the possibility that the investment by firm 1 allows firm 2 to improve on its product in such a way that it can be competitive enough to sell, whereas in the absence of the spillovers it would have not been able to attract any consumer in either market. This happens in the following region.

- From $f \phi$ to $f e$.

\section{Conclusions}

In this paper we have analyzed a very simple model to analyze in a formal framework whether multinational firms must have some kind of firm specific advantages with respect to local enterprises. It is found that such advantages are not necessary to establish a foreign subsidiary. Further, it might be that a firm decides to make a foreign direct investment to try and appropriate advantages possessed by firms located in the host country, thanks to the existence of technological spillovers which occur when production is located in the same area. 


\section{References}

Blomström, M. and A. Kokko (1996) "Multinational corporations and spillovers", CEPR Discussion Paper Series, No. 1365.

Brainard, S.L. (1993) "An empirical assessment of the proximity-concentration trade-offbetween multinational sales and trade", NBER Working Paper Series, No. 4580.

Horstmann, I. and J. Markusen (1992) "Endogenous markets structures in international trade" Journal of International Economics, 33, 109-129.

Hummels D.L. and R.M. Stern (1994) "Evolving pattern of North American merchandise trade and foreign direct investment, 1960-1990", The World Economy, 1994, 17 (1), 5-29.

Hymer, S.H. (1976) The international operations of national firms: A study of direct foreign investment, Cambridge, Ma.: The MIT Press.

Markusen, James R. (1995) "The boundaries of multinational enterprises and the theory of international trade", Journal of Economic Perspectives, $9(2)$, Spring, pp.169-189.

Neven, D. and G. Siotis (1995) "Technology sourcing fdi in the EC: An empirical evaluation", Universit de Lausanne, mimeo.

Motta, M. (1992) "Multinational firms and the tariff-jumping argument. A game theoretic analysis with some unconventional conclusions." European Economic Review, 36, 1557-1571.

Motta, M. (1994) "International trade and investments in a vertically differentiated industry", International Journal of Industrial Organization, $12,179-196$.

Singh N. and X. Vives (1984) "Price and quantity competition in a differentiated oligopoly, Rand Journal of Economics, 15, 546-554.

Smith, A. (1987) "Strategic investments, multinational corporations and trade policy", European Economic Review, 31, 89-96. 


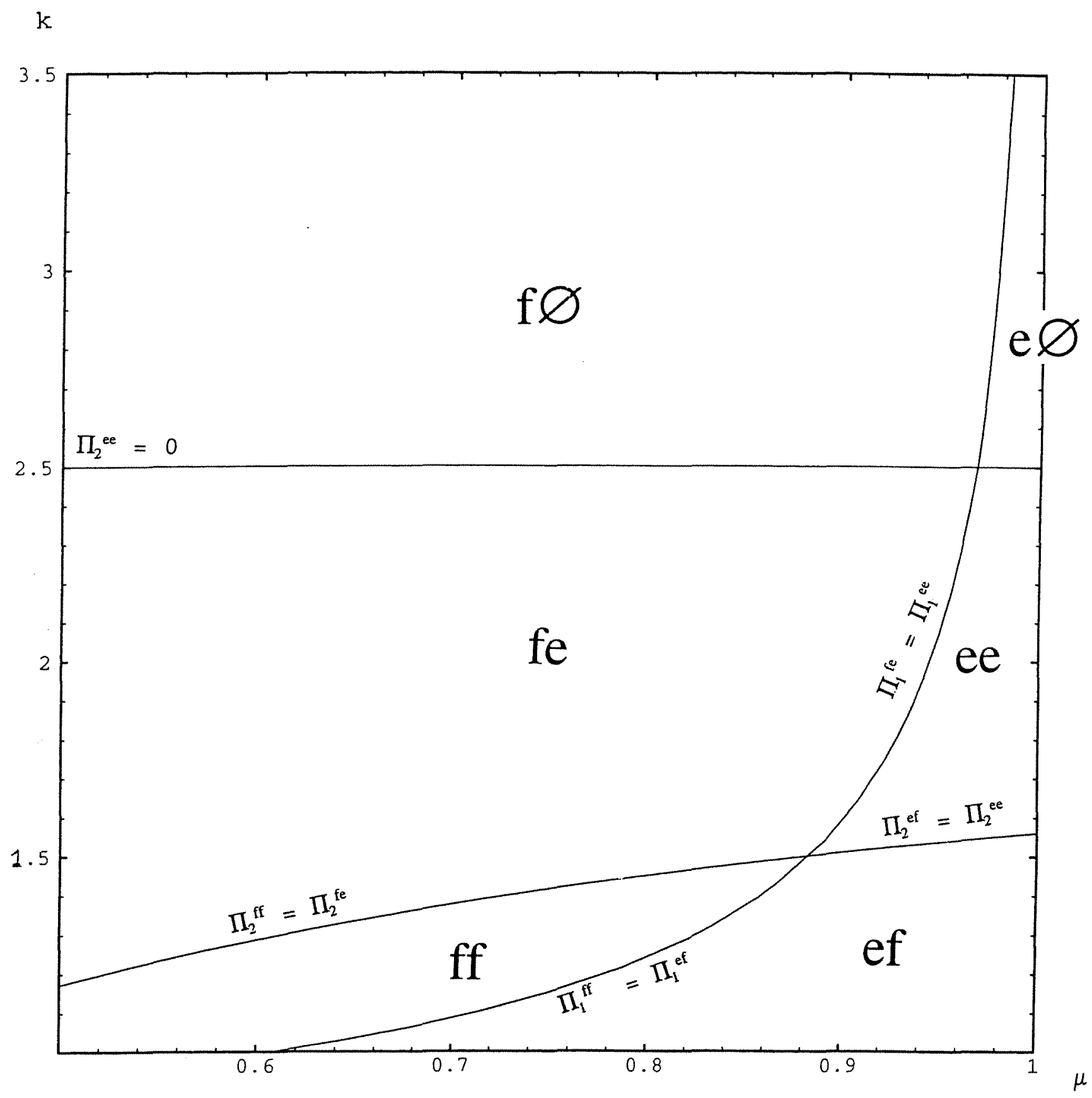

Figure 1 - Foreign investments (f) and export (e) decisions without spillovers.

Equilibrium configuration computed for the following values: $g=.8, F=1, \lambda=0, S=10, t=2$. 
k

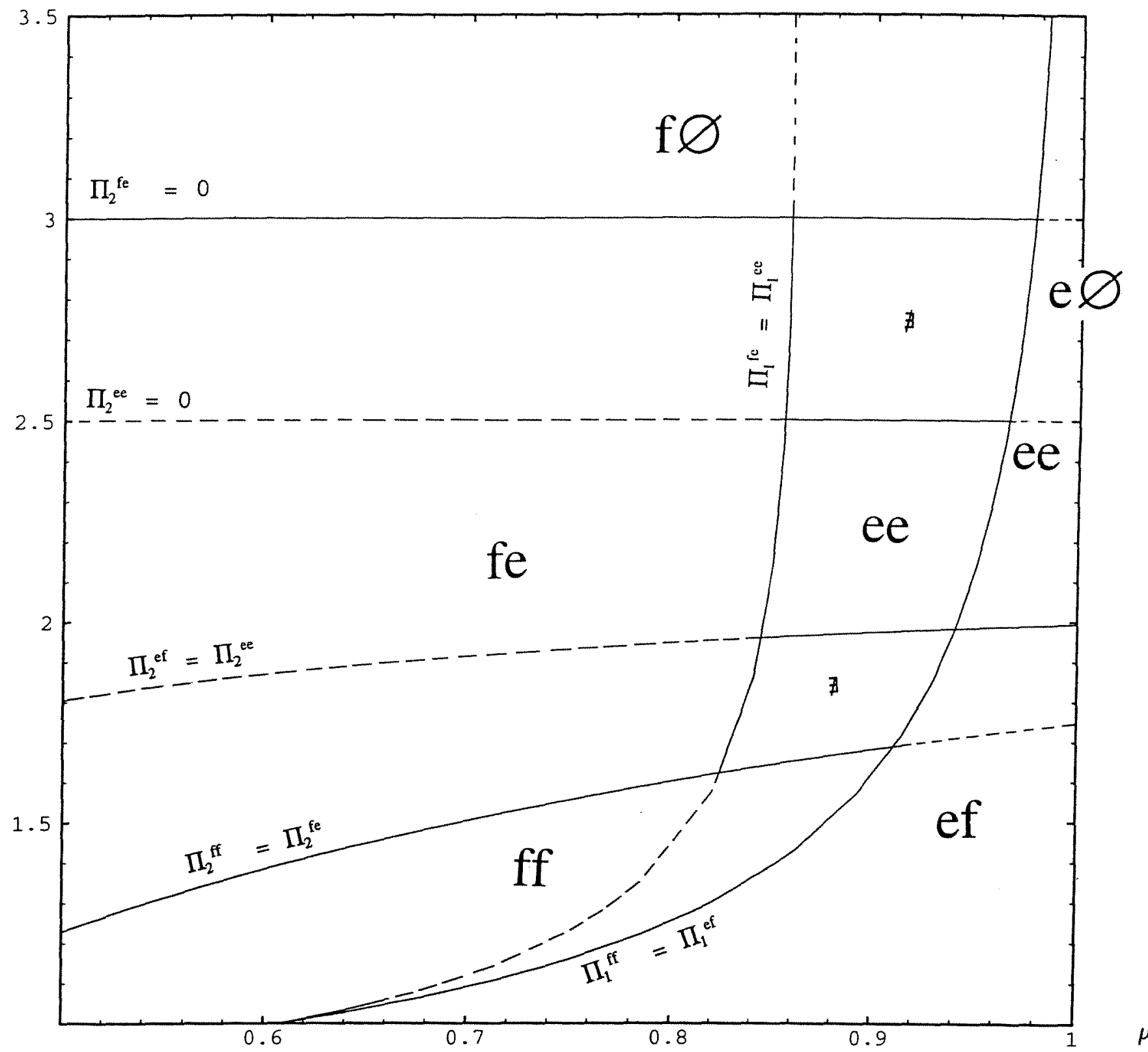

Figure 2 - Foreign investments (f) and export (e) decisions with spillovers.

Equilibrium configuration computed for the following values: $g=8, F=1, \lambda=1, S=10, t=2$. 


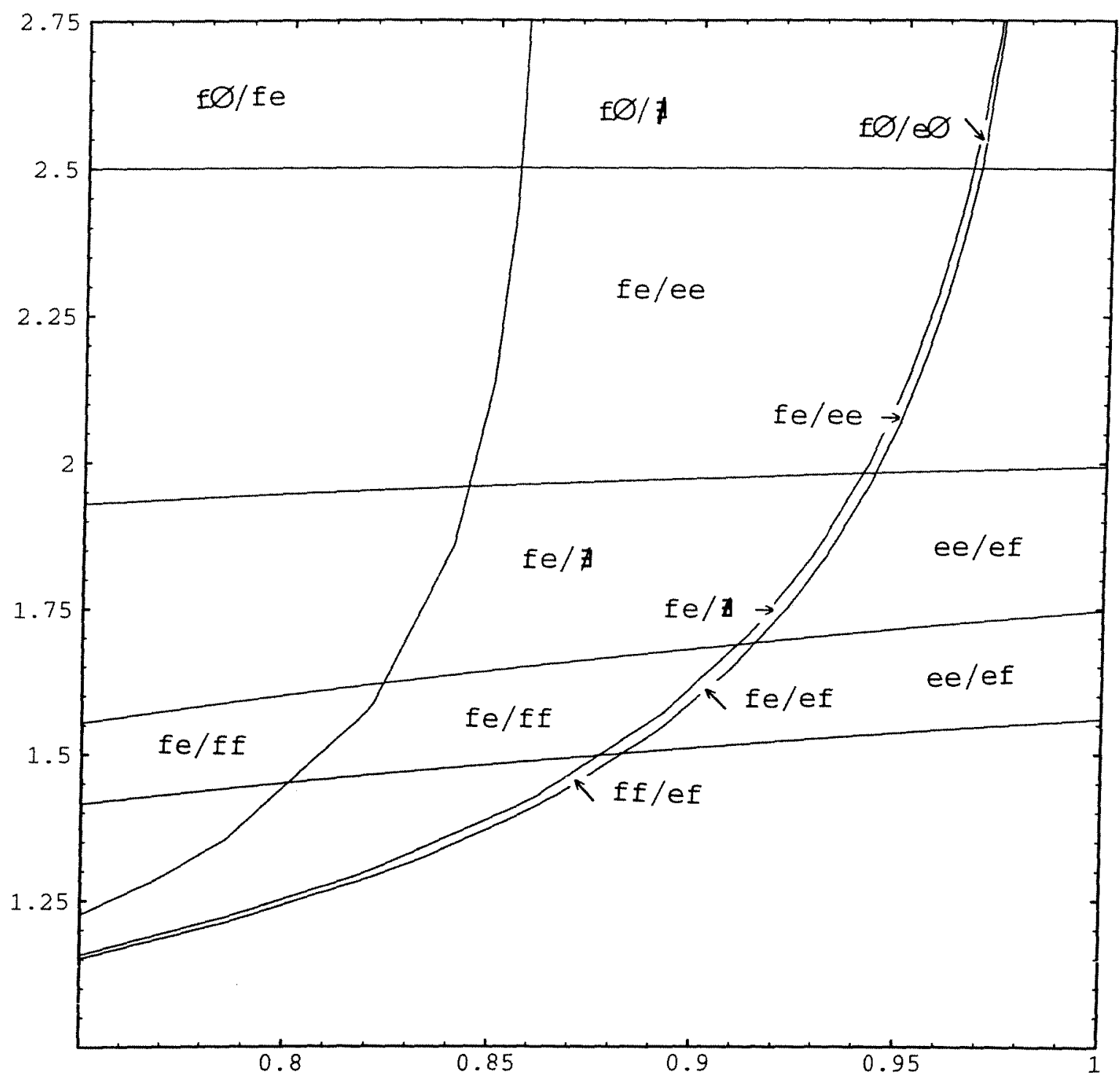

Figure 3 - Changes in equilibrium configurations when increasing $\lambda$ from 0 to 1 .

Curves drawn for the following values of the other parameters: $g=.8, F=1, S=10, t=2$. 